\title{
The 1-year safety and efficacy outcomes of Absorb bioresorbable vascular scaffolds for coronary artery disease treatment in diabetes mellitus patients: the ABSORB DM Benelux study
}

\author{
T. M. Hommels · R. S. Hermanides · S. Rasoul · B. Berta · A. J. J. IJsselmuiden · G. A. J. Jessurun · E. Benit · \\ B. Pereira · G. De Luca · E. Kedhi
}

Published online: 13 June 2019

(C) The Author(s) 2019

\begin{abstract}
Background Diabetes mellitus (DM) patients show higher rates of repeat revascularisation even in the era of modern drug-eluting stents (DES). The concept of bioresorbable scaffolds is becoming captivating, as it might allow for repeat interventions, prolonging the time span during which patients can be treated by percutaneous coronary intervention (PCI).

Aims We intend to evaluate the short- and long-term safety and efficacy of Absorb bioresorbable vascular scaffolds (Absorb BVS) in the treatment of coronary
\end{abstract}

\section{Trial ID: NTR5447}

Availability of data and materials The datasets used and/or analysed during the current study are available from the corresponding author, T.M. Hommels, on reasonable request.

Electronic supplementary material The online version of this article (https://doi.org/10.1007/s12471-019-1293-7) contains supplementary material, which is available to authorised users.

T. M. Hommels $(\bowtie) \cdot$ R. S. Hermanides · B. Berta ·

G. De Luca E. Kedhi

Isala Klinieken, Zwolle, The Netherlands

t.m.hommels@isala.nl

S. Rasoul

Zuyderland Medisch Centrum, Heerlen, The Netherlands

A. J. J. IJsselmuiden

Albert Schweitzer Ziekenhuis, Dordrecht, The Netherlands

G. A. J. Jessurun

Scheper Ziekenhuis, Emmen, The Netherlands

E. Benit

Virga Jesse Ziekenhuis, Hasselt, Belgium

B. Pereira

Institut National de Chirurgie Cardiaque et de Cardiologie Interventionnelle, Luxembourg, Luxembourg artery disease (CAD) in DM patients for any indication.

Methods The ABSORB DM Benelux is an international prospective study in DM patients who have undergone PCI with $\geq 1$ Absorb BVS. Major adverse cardiac events (MACE) at 1 year was the primary endpoint, defined as a composite of all-cause death, any myocardial infarction (MI) and ischaemia-driven target vessel revascularisation (TVR). Secondary endpoints were target lesion failure (TLF) and definite or probable scaffold thrombosis (ScT).

Results Between April 2015 and March 2017, 150 DM patients and 188 non-complex lesions were treated. Device implantation was successful in 100\%. MACE occurred in $14(9.5 \%)$ patients, with all-cause death occurring in $4(2.7 \%)$, any MI in $6(4.1 \%)$ and ischaemia-driven TVR in 7 (4.8\%) respectively. TLF was reported in $11(7.5 \%)$. Definite and probable ScT was observed in 2 (1.4\%).

\section{What's new?}

- This is the first prospective study utilising Absorb bioresorbable vascular scaffolds for treatment of anatomically low-risk patients with diabetes mellitus for any indication.

- Acceptable safety and efficacy outcomes were obtained at 1-year follow-up.

- A low incidence of scaffold thrombosis was observed with no occurrences of late thrombosis.

- If these promising results are confirmed after a longer follow-up period, more performant bioresorbable scaffolds might open new horizons for treatment of coronary artery disease in diabetes mellitus patients. 
Conclusion Absorb BVS for treatment of anatomically low-risk patients with DM show acceptable safety and efficacy outcomes at 1 year. If these promising results are confirmed after a longer follow-up period, newgeneration bioresorbable scaffolds combined with refinement of implantation techniques might open new horizons for CAD treatment in DM patients.

Keywords Bioresorbable scaffold · Diabetes mellitus . Coronary artery disease $\cdot$ Percutaneous coronary intervention · Scaffold thrombosis

\section{Introduction}

The incidence and prevalence of diabetes mellitus (DM) is increasing in both developed and developing countries [1, 2]. People with DM are between 2 and 4 times more likely to develop coronary artery disease (CAD) compared to non-DM patients [3-6]. Despite the major advances in percutaneous coronary intervention (PCI) with newer generations of drug-eluting stents (DES) accompanied by improved medical treatment, studies have continued to show a trend towards higher rates of major adverse cardiovascular events in DM patients compared to non-DM patients [7, 8].

Bioresorbable polymer drug-eluting scaffold systems enable the application of a short-term vessel scaffold (which subsequently dissolves) combined with drug delivery capability. The short-term results from the Absorb bioresorbable vascular scaffolds (Absorb BVS) clinical trial programs, at the time the study was designed, showed promising safety and efficacy outcomes for these devices, being non-inferior to those of the best-in-class durable polymer everolimus-eluting stents (EES) [9-15]. Considering the scaffold resorption, it was conceivable that vessel restoration following Absorb BVS implantation might be associated with more favourable longterm outcomes compared to metallic DES, mainly because inflammation induced by foreign bodies is only transient following Absorb BVS implantation while it is permanent after metallic DES implantation. Particularly in DM patients, where diabetes-related chronic peristrut inflammation triggers more aggressive restenosis, reduction of permanent inflammatory triggers may further improve clinical outcomes. Furthermore, repeat interventions at target lesions could be effectuated multiple times without a critical loss of vessel diameter, thus prolonging the time interval during which CAD in DM patients could still be managed by PCI. Henceforth, we designed the ABSORB DM Benelux Study to evaluate the short- and longterm safety and efficacy of the Absorb BVS in patients with DM.

\section{Methods}

The ABSORB DM Benelux Study is an international study in patients with DM and de novo lesions treated with the ABSORB family and conducted in The Netherlands, Belgium and Luxembourg. This clinical investigation is a prospective register and did not test any new device. The study was approved in February 2015, in accordance with the Declaration of Helsinki, by the Ethical Committees of each participating centre.

\section{Study population}

All patients aged $\geq 18$ years with a history of DM undergoing PCI with implantation of $\geq 1$ Absorb BVS for any indication, in a de novo lesion located in a native non-grafted artery, could be enrolled. The exclusion criteria were determined as: pregnancy; patients unable to provide (written) informed consent; known left ejection fraction $<30 \%$; life expectancy $<3$ years and inability to undergo dual antiplatelet therapy (DAPT) for at least 12 months.

\section{Endpoints and definitions}

The primary endpoint was the incidence of major adverse cardiac events (MACE) at 1 year, defined as a composite of all-cause death, any myocardial infarction (MI) and ischaemia-driven target vessel revascularisation (TVR). The secondary endpoints represented target lesion failure (TLF), defined as a composite of cardiac death (CD), target vessel MI and ischaemia-driven target lesion revascularisation (TLR), the incidence of definite or probable scaffold thrombosis (ScT) and the 1-year incidence rates of the endpoint composites. Adverse event definitions are described in the Supplementary Table.

\section{$\mathrm{PCl}$ procedure}

The implanted devices are the bioresorbable polymer drug-eluting scaffold ABSORB BVS system and the ABSORB GT1 system (Abbott Vascular, Santa Clara, CA, USA). These devices are composed of poly-L-lactic acid and an everolimus-eluting polymer coating of poly-DL-lactic-acid, both of which are completely bioresorbable through a natural metabolic process within 3 years [16]. The average strut thickness is $150 \mu \mathrm{m}$. The device was available in diameters ranging from 2.5 to $3.5 \mathrm{~mm}$ with a length of $8,12,18,24$, or $28 \mathrm{~mm}$. Implantation of an Absorb BVS was at the discretion of the operator. The vessel size, similar to other trials with this particular device, ranged from 2.50 to $3.75 \mathrm{~mm}$. Predilatation and postdilatation were strongly recommended. Intracoronary imaging by means of optical coherence tomography (OCT) or intravascular ultrasound (IVUS) was encouraged but not mandatory. Treatment of bifurcations was not encouraged; however, in this case a provisional T-stenting technique was advised. There were no limitations regarding lesion length; however, treatment of very calcified and tortuous lesions was not encour- 
aged. If found necessary, additional implantation of metallic DES was accepted as a bailout procedure. Angiographic success was defined as a visually assessed $<30 \%$ residual stenosis of the target lesion after successful device implantation. Procedural success was defined as angiographic success with no occurrence of events during the procedure. All patients received DAPT for at least 12 months.

\section{Follow-up and assessment of adverse events}

Clinical follow-up included clinical visits and telephone contact. All reported adverse cardiac events underwent assessment by an independent clinical event committee (Diagram BV, Zwolle, The Netherlands). Angiographic evaluations of baseline as well as repeat angiograms in patients with events were analysed by means of quantitative coronary angiography, Thrombolysis in Myocardial Infarction (TIMI) as well as presence of thrombus analysis by an independent core laboratory (Diagram BV, Zwolle, The Netherlands).

\section{Statistical analysis}

The baseline clinical and angiographic characteristics are presented using descriptive statistics. Categorical variables are summarised as frequency and percentages. Continuous variables are summarised as mean and standard deviation. The composite endpoints and clinical events are presented by using the Kaplan-Meier survival method with time-to-event analysis. In addition, a multivariate Cox regression model with adjustment for age, gender, PCI indication (acute coronary syndrome versus non-acute coronary syndrome) and insulin-treated DM was performed and presented with hazard ratio (HR) and 95\% confidence interval (CI). Other regression models were performed for relevant factors such as multivessel or multiple lesion treatment ( $\geq 2$ vessels/lesions), proximal versus distal segment implantation (proximal coronary location-segment number $1,5,6,11$ versus none), number of devices used for target lesion, total length of implanted devices, employment of intracoronary imaging and utilisation of pre- and postdilatation. A $p$ value $<0.05$ was considered to indicate formal statistical significance. The analyses were conducted with intention-to-treat. All statistical analyses were performed using SPSS version 25 (IBM Corp., Armonk, NY, USA).

\section{Results}

Between April 2015 and March 2017, a total of 150 DM patients and 188 lesions were treated by PCI with implantation of Absorb BVS. The patients were treated in 18 different centres by experienced Absorb BVS operators. Their baseline clinical characteristics are shown in Tab. 1. The patients had a mean age of $63.4 \pm 10.4$ years and were predominantly male (72\%). DM type II was diagnosed in $93.3 \%$ and insulin-treated DM at hospital admission was $31.3 \%$.

The angiographic characteristics are described in Tab. 2. The 188 target lesions were treated with a total of 214 implanted devices (ABSORB BVS 60.7\%, ABSORB GT1 $34.1 \%$ and metallic DES $5.1 \%$ in addition to implantation of $\geq 1$ Absorb BVS). Device implantation was successful in $100 \%$ of the patients and the procedural success was $99.5 \%$ with a single patient developing a distal coronary dissection after implantation of an ABSORB BVS with good clinical evolution. Predilatation was performed in $93.3 \%$ and postdilatation in $75.5 \%$ of the procedures. In no case was postdilata-

Table 1 Clinical characteristics of the patients at baseline

\begin{tabular}{|c|c|}
\hline Baseline clinical characteristic & Patients $(n=150)$ \\
\hline Age (years)-mean $\pm S D$ & $64.3 \pm 10.4$ \\
\hline Sex (male) $-n(\%)$ & $108(72.0)$ \\
\hline Race (Caucasian) - $n(\%)$ & $140(93.3)$ \\
\hline Body-mass index $\left(\mathrm{kg} / \mathrm{m}^{2}\right)$-mean $\pm \mathrm{SD} ; n$ & $29.5 \pm 5.1 ; 148^{a}$ \\
\hline \multicolumn{2}{|l|}{ Risk factors - $n(\%)$} \\
\hline Diabetes mellitus type 1 & $10(6.7)$ \\
\hline Diabetes mellitus type 2 & $140(93.3)$ \\
\hline Insulin-dependent diabetes mellitus & $47(31.3)$ \\
\hline Diabetes mellitus treated with oral antidiabetic & $117(78.0)$ \\
\hline $\mathrm{HbA} 1 \mathrm{c}$ at hospitalisation $(\mathrm{mmol} / \mathrm{mol})$ - mean $\pm \mathrm{SD} ; n$ & $55.5 \pm 11.5 ; 42^{a}$ \\
\hline Arterial hypertension & $104(69.3)$ \\
\hline Hypercholesterolaemia & $100(66.7)$ \\
\hline Family history of cardiovascular disease & $59(39.3)$ \\
\hline Current smoker & $35(23.3)$ \\
\hline \multicolumn{2}{|l|}{ Medical history-n (\%) } \\
\hline Previous ACS & $41(27.3)$ \\
\hline Previous PCl & $37(24.7)$ \\
\hline Previous CABG & $8(5.3)$ \\
\hline Previous CVA or TIA & $10(8.7)$ \\
\hline Severe chronic renal failure ${ }^{b}$ & $4(2.7)$ \\
\hline Chronic pulmonary obstructive disease ${ }^{c}$ & $11(7.3)$ \\
\hline \multicolumn{2}{|l|}{ Clinical presentation-n (\%) } \\
\hline Acute coronary syndrome & $73(48.7)$ \\
\hline ST-segment elevation myocardial infarction & $18(12.0)$ \\
\hline Non-ST-segment elevation myocardial infarction & $29(19.3)$ \\
\hline Unstable angina pectoris & $26(17.3)$ \\
\hline Non-acute coronary syndrome & $77(51.3)$ \\
\hline Stable angina pectoris & $59(39.3)$ \\
\hline Silent ischaemia & $8(5.3)$ \\
\hline Other & $10(6.7)$ \\
\hline \multicolumn{2}{|c|}{$\begin{array}{l}\text { Plus-minus values are means } \pm \text { standard deviation } \\
\text { ACS acute coronary syndrome, } P C I \text { percutaneous coronary intervention, } \\
C A B G \text { coronary artery bypass grafting, CVA cerebrovascular accident, } \\
T I A \text { transient ischaemic attack } \\
\text { altalic numbers represent the known total from which the variable was } \\
\text { calculated } \\
\text { 'Renal insufficiency was defined as estimated glomerular filtration } \\
\text { rate of less than } 30 \mathrm{ml} / \mathrm{min} \text { per } 1.73 \mathrm{~m}^{2} \text { of body surface area (GFR } \\
<30 \mathrm{ml} / \mathrm{min} / 1.73 \mathrm{~m}^{2} \text { ) } \\
{ }^{\circ} \text { Chronic pulmonary obstructive disease was defined as } \geq \text { Gold class II }\end{array}$} \\
\hline
\end{tabular}


Table 2 Angiographic characteristics of the patients at baseline

\begin{tabular}{|c|c|}
\hline \multicolumn{2}{|l|}{ Baseline angiographic characteristics } \\
\hline \multicolumn{2}{|l|}{ Patient-level analysis } \\
\hline Number of patients & 150 \\
\hline Number of treated target lesions-mean $\pm \mathrm{SD}$ & $1.3 \pm 0.5$ \\
\hline Treated target lesions $\geq 2-n(\%)$ & $30(20.0)$ \\
\hline Number of treated target vessels-mean \pm SD & $1.1 \pm 0.3$ \\
\hline Treated target vessels $\geq 2-n(\%)$ & $12(8.0)$ \\
\hline $\begin{array}{l}\text { Devices implanted in proximal coronary segment } \\
-n(\%)^{b}\end{array}$ & $57(38.0)$ \\
\hline \multicolumn{2}{|l|}{ Lesion-level analysis } \\
\hline Number of lesions & 188 \\
\hline \multicolumn{2}{|l|}{ Coronary artery lesion distribution— $n(\%)$} \\
\hline Right coronary artery & $57(30.3)$ \\
\hline Left anterior descending artery & $89(47.3)$ \\
\hline Circumflex artery & $40(21.3)$ \\
\hline Arterial or venous graft & $2(1.1)$ \\
\hline \multicolumn{2}{|l|}{ Coronary artery lesion characteristics } \\
\hline Visual estimated diameter stenosis—-mean $\pm \mathrm{SD} ; n^{c}$ & $85.5 \pm 11.9 ; 181^{a}$ \\
\hline Bifurcation- $n(\%)$ & $27(14.4)$ \\
\hline \multicolumn{2}{|l|}{ Device-level analysis } \\
\hline Number of devices & 214 \\
\hline \multicolumn{2}{|l|}{ Device distribution- $n(\%)$} \\
\hline ABSORB BVS & $130(60.7)$ \\
\hline ABS0RB GT1 & $73(34.1)$ \\
\hline Metallic DES & $11(5.1)$ \\
\hline \multicolumn{2}{|l|}{ Number of devices at lesion— $n$ (\%) } \\
\hline 1 & $168(89.4)$ \\
\hline 2 & $16(8.5)$ \\
\hline 3 & $2(1.1)$ \\
\hline 4 & $2(1.1)$ \\
\hline Number of devices per lesion—mean $\pm \mathrm{SD}$ & $1.1 \pm 0.5$ \\
\hline Device diameter-mean $\pm S D$ & $3.0 \pm 0.4$ \\
\hline Inflation pressure-mean $\pm \mathrm{SD} ; n^{d}$ & $14.3 \pm 2.6 ; 211^{\mathrm{a}}$ \\
\hline Total treated length—-mean $\pm S D$ & $29.7 \pm 19.0$ \\
\hline \multicolumn{2}{|l|}{ Procedure-level analysis } \\
\hline \multicolumn{2}{|l|}{ Results-n (\%) } \\
\hline Visual diameter stenosis postprocedure $<30 \%$ & $185^{\mathrm{a}}(100)$ \\
\hline Postprocedural TIMI grade 3 & $186^{a}(100)$ \\
\hline Angiographic success & $188(100)$ \\
\hline Device implantation success & $188(100)$ \\
\hline Procedural success & 187 (99.5) \\
\hline \multicolumn{2}{|l|}{ Peri-implantation procedures } \\
\hline FFR measurement- $n(\%)$ & $26(13.8)$ \\
\hline Preimplantation OCT or IVUS— $n(\%)$ & $14(7.4)$ \\
\hline Predilatation- $n(\%)$ & $177(94.1)$ \\
\hline Predilatation balloon size-mean $\pm \mathrm{SD} ; n$ & $2.8 \pm 0.8 ; 176^{\natural}$ \\
\hline Predilatation pressure-mean $\pm \mathrm{SD} ; n^{\mathrm{d}}$ & $14.8 \pm 4.0 ; 174^{a}$ \\
\hline Postdilatation- $n(\%)$ & $142(75.5)$ \\
\hline Postdilatation balloon size-mean \pm SD & $3.2 \pm 0.5$ \\
\hline Postdilatation pressure-mean $\pm \mathrm{SD}^{\mathrm{d}}$ & $17.3 \pm 4.3$ \\
\hline
\end{tabular}

Table 2 (Continued)

\begin{tabular}{|c|c|}
\hline \multicolumn{2}{|l|}{ Baseline angiographic characteristics } \\
\hline $\begin{array}{l}\text { Postdilatation balloon size }>0.5 \mathrm{~mm} \text { larger than } \\
\text { scaffold size }-n(\%)\end{array}$ & 0 \\
\hline Postimplantation OCT or IVUS— $n(\%)$ & $15(8.0)$ \\
\hline $\begin{array}{l}\text { Plus-minus values are means } \pm \text { standard devia } \\
\text { Length of lesions, devices and balloons were } \mathrm{m} \\
\text { (mm), as was the diameter of the devices } \\
D E S \text { drug-eluting stents, PCI percutaneous co } \\
\text { TIMI Thrombolysis in Myocardial Infarction with } \\
\text { as completely restored flow, FFR fractional flov } \\
\text { coherence tomography, IVUS intravascular ultras } \\
\text { altalic numbers represent the known total from } \\
\text { calculated } \\
\text { bProximal devices were defined as implantation } \\
11 \\
\text { cVisual estimated diameter stenosis was defined }\end{array}$ & $\begin{array}{l}\text { in millimetres } \\
\text { ntervention, } \\
3 \text { referenced } \\
\text { e, OCT optical } \\
\text { e variable was } \\
\text { segments } 1,5,6 \text {, } \\
\text { centage }\end{array}$ \\
\hline
\end{tabular}

tion balloon size more than $0.5 \mathrm{~mm}$ larger than the scaffold size. Preimplantation, intracoronary imaging with OCT and IVUS was conducted in $7.4 \%$ and $1.0 \%$ respectively. Postimplantation, OCT was effectuated in $6.4 \%$ and IVUS in $1.6 \%$, mostly for the purpose of apposition control. Postprocedural TIMI grade 3 was observed after all procedures.

\section{Clinical outcomes}

All patients received a complete 1-year follow-up. Three patients $(2.0 \%)$ were lost to follow-up during this period. At 1-year follow-up, $72.7 \%$ of the patients were still receiving DAPT. The clinical outcomes at 1 year are presented in Tab. 3 and corresponding Figs. 1 and 2. MACE occurred in 14 patients (9.5\%), with all-cause death occurring in $4(2.7 \%)$, any MI in $6(4.1 \%)$ and ischaemia-driven TVR in 7 (4.8\%) respectively. TLF was observed in 11 patients $(7.5 \%)$, with CD occurring in 4 (2.7\%), target vessel MI in 4 (2.7\%) and ischaemia-driven TLR in $4(2.8 \%)$ respectively. Although 2 deaths resulted from progression of malignancy, judging them as CD could not be avoided. Of the recorded target vessel MIs, 2 (1.4\%) were periprocedural. Definite and probable ScT was observed in $2(1.4 \%)$ patients. One 80 -year-old male patient had a definite ScT after treatment of a single vessel and a single lesion with an ABSORB GT1 in the proximal circumflex artery for an acute coronary syndrome. He presented with an acute MI 8 days after the procedure and underwent successful revascularisation. At the index procedure predilatation was carried out, but no postdilatation or intracoronary imaging was performed. The second patient, a 62-year-old male, with treatment of a single vessel and a single lesion with an ABSORB GT1 in the proximal left anterior descending artery for a non-acute coronary syndrome indication, died of an unknown cause the day after discharge and was regarded as a probable ScT. At the index procedure, pre- and postdilatation were conducted, but intracoronary imaging was not performed. Finally, in a multivariate Cox regression analysis adjusting 
Table 3 Safety and efficacy outcomes at 1-year followup

\begin{tabular}{|c|c|}
\hline Endpoints and clinical events— $\%(n)$ & Patients $(n=147)$ \\
\hline Primary endpoint: MACE ${ }^{\mathrm{a}}$ & $9.5(14)$ \\
\hline All-cause death & $2.7(4)$ \\
\hline Any myocardial infarction & $4.1(6)$ \\
\hline Ischaemia-driven target vessel revascularisation & $4.8(7)$ \\
\hline Target lesion failure ${ }^{\mathrm{b}}$ & $7.5(11)$ \\
\hline Cardiac death & $2.7(4)$ \\
\hline Target vessel myocardial infarction & $2.7(4)$ \\
\hline Periprocedural myocardial infarction & $1.4(2)$ \\
\hline Ischaemia-driven target lesion revascularisation & $2.8(4)$ \\
\hline Definite or probable scaffold thrombosis & $1.4(2)$ \\
\hline Early: $0-30$ days & $1.4(2)$ \\
\hline Acute: $\leq 24 \mathrm{~h}$ & 0 \\
\hline Subacute: $>24 \mathrm{~h}-30$ days & $1.4(2)$ \\
\hline Late: 31 days: $\leq 1$ year & 0 \\
\hline Very late: $>1$ year & 0 \\
\hline Definite & $0.7(1)$ \\
\hline Probable & $0.7(1)$ \\
\hline \multicolumn{2}{|c|}{$\begin{array}{l}\text { The clinical outcomes represented as endpoints and clinical events at } \\
1 \text {-year follow-up. Three patients were lost to follow-up. Endpoints and } \\
\text { clinical events are presented by Kaplan-Meier estimates. Angiographic } \\
\text { evaluations of baseline as well as repeat angiograms in patients with } \\
\text { events were analysed by means of quantitative coronary angiography, } \\
\text { Thrombolysis in Myocardial Infarction as well as presence of thrombus } \\
\text { analysis by an independent core laboratory (Diagram BV, Zwolle, The } \\
\text { Netherlands) } \\
\text { aMajor adverse cardiac events (MACE) were defined as a composite of } \\
\text { all-cause death, any myocardial infarction and ischaemia-driven target } \\
\text { vessel revascularisation } \\
\text { bTarget lesion failure was defined as a composite of cardiac death, } \\
\text { target vessel myocardial infarction and ischaemia-driven target lesion } \\
\text { revascularisation }\end{array}$} \\
\hline
\end{tabular}

for age, gender and PCI indication, insulin-treated DM was the only variable that showed a trend toward predicting MACE (HR 2.76; 95\% CI: 0.94-8.07; $p=0.06$ ).

\section{Discussion}

The Benelux ABSORB DM Study, the first dedicated prospective study with utilisation of Absorb BVS for percutaneous treatment of CAD in $\mathrm{DM}$ patients for any indication in non-complex anatomy shows acceptable safety and efficacy outcomes in this clinically high-risk patient population.

The efficacy outcomes observed in our study are similar to the 1-year results of the ABSORB III trial with very comparable clinical outcomes for ischaemia-driven TVR and ischaemia-driven TLR [17]. Similarly, the TLF data were almost identical. Also, the reported ScT incidence was similar in both trials. Although ABSORB III included only 31.5\% DM patients and no patients with ongoing MI, both studies share a relatively low lesion risk and therefore, as previously shown, simple lesions behave similarly in DM and non-DM patients after PCI [18].
Compared to 1-year DM sub-analysis of the ABSORB trials, we observed a similar incidence of TLF, ischaemia-driven TVR and ischaemia-driven TLR. However, the incidences of the safety outcomes like ScT and target vessel MI were somewhat lower in our study [19]. While clinical and angiographic baseline characteristics were similar, the observed safety differences may be explained by the longer experience in the handling of Absorb BVS of the participating centres in our study. Indeed, postdilatation balloon size was never more than $0.5 \mathrm{~mm}$ larger than scaffold size, showing strict compliance with the procedure protocol.

Comparing the performance of the Absorb BVS to EES in DM patients of the SPIRIT V diabetic study, Absorb BVS has a lower incidence of MACE, TLF, ischaemia-driven TVR and TLR with comparable incidences of target vessel MI at 1-year follow-up [20]. The patient groups had corresponding angiographic characteristics but there are non-negligible racial differences between both studies. Furthermore, our study showed similar safety and efficacy outcomes with EES used in DM patients in a pooled database of SPIRIT and COMPARE trials, as was also found in a propensity score matched comparison of the ABSORB EXTEND and the SPIRIT trials [7, 21].

The rationale for bioresorbable scaffolds derives from previous evidence that consistently reported that DM patients suffer worse outcomes with PCI as compared to coronary artery bypass grafting (CABG) $[22,23]$. However, PCI is still performed in DM patients, particularly in those with single vessel disease as well as multivessel disease with a low SYNTAX score, as is consistent with the results from the SYNTAX trial [24]. Considering the accelerated nature of coronary atherosclerosis disease, CAD presents at a younger age in DM patients. Therefore, maintaining these patients free of ischaemia over decades becomes challenging. While CABG is indeed the treatment of choice for advanced multivessel disease in this patient population, it is known that venous grafts have a limited patency, giving PCI an important role in delaying the time at which these patients ultimately undergo CABG [25]. From this perspective, efforts to improve PCI outcomes in early-stage CAD in DM patients become paramount.

Furthermore, a large analysis of a pooled database of 18 clinical trials has shown that in the DES era, clinical outcomes after PCI in DM patients are highly dependent on lesion complexity at baseline with simple lesions being associated with similar efficacy outcomes to those in non-DM patients [18]. These data suggest that PCI may have favourable outcomes in a well-selected group of patients with DM, provided the extent of disease is less complex. However, progressive restenosis remains problematic with metallic DES, as the number of possible re-interventions is limited. Conversely, resorbable scaffolds are becoming attractive in this particular setting considering the theoretically larger number of possible re-interven- 
Fig. 1 Kaplan-Meier estimates of a primary endpoint major adverse cardiac events and $\mathbf{b}$ target lesion failure at 1-year follow-up. MACE major adverse cardiac events, TLF target lesion failure, KM Est KaplanMeier estimate, $\mathrm{Cl}$ confidence interval
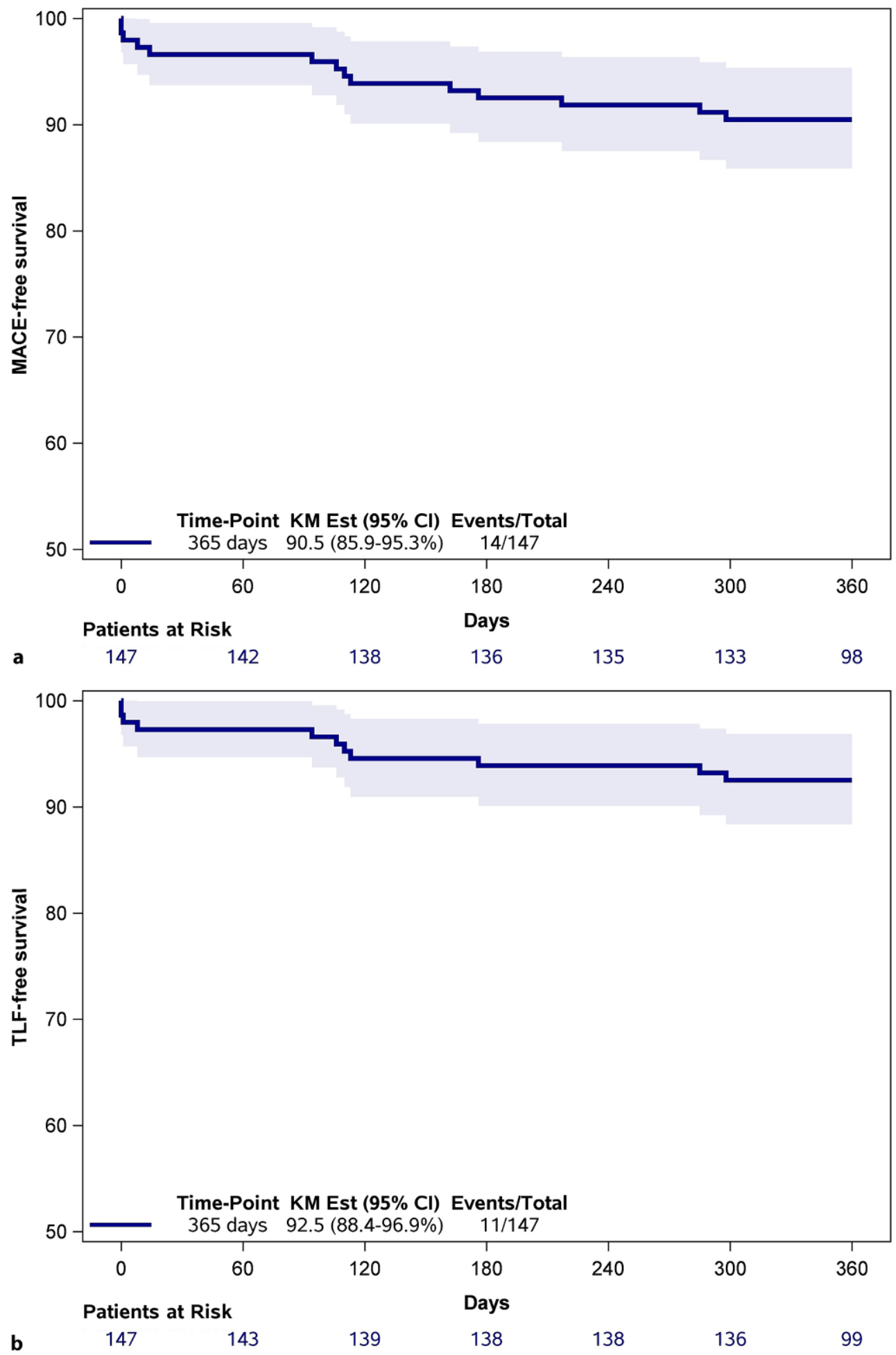

tions and thus extending the time span during which these patients could still be treated percutaneously.

On the basis of the above, the 1-year results of our study, which showed that Absorb BVS has promising safety and efficacy outcomes post-PCI in DM patients with non-extensive $C A D$, stimulate further research in this direction. If maintained up to 3 years, the expected resorption period of this device, this treat- ment may herald brighter perspectives for PCI in DM patients. Whether this would be the case remains questionable, as the long-term follow-up safety outcomes from the AIDA and ABSORB III trials were unfavourable for Absorb BVS in comparison with EES $[26,27]$. On the other hand, these trials also brought to light the importance of the scaffold implantation technique and the advantageous role of longer DAPT 
Fig. 2 One-year KaplanMeier estimates of each of the composites of the endpoints. For scaffold thrombosis an explicit difference has been made between definite (b/ue) and probable (red), both accounting for $0.7 \%$ of the total $1.4 \%$. There were no occurrences of late definite or probable scaffold thrombosis. MI myocardial infarction, TVR target vessel revascularisation, TLR target lesion revascularisation, ScT scaffold thrombosis

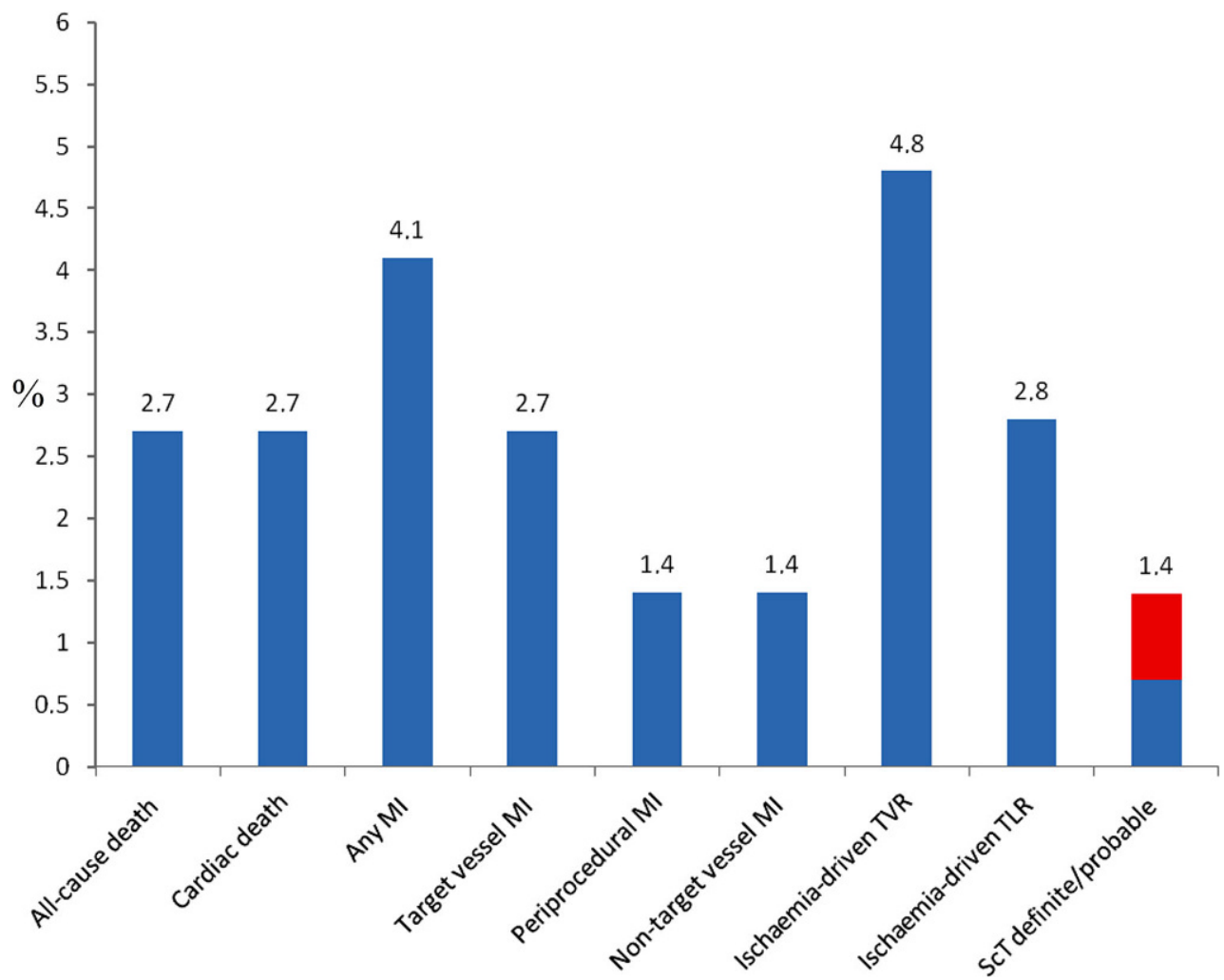

uate the performance of the Absorb BVS in this specific group of patients.

\section{Conclusion}

The results of this multinational dedicated prospective study show that PCI with Absorb BVS for treatment of non-extensive CAD in DM patients, performed by experienced operators, is associated with acceptable safety and efficacy outcomes at 1 year when historically comparable to modern DES. If maintained for longer follow-up periods, covering the resorption phase of the device, our study results would further reinforce the potentially advantageous impact of bioresorbable scaffolds for CAD treatment in fast progressing atherosclerosis populations like DM patients, where PCI even with modern DES remains challenging. From this perspective, it could pave the way for further research with new-generation and more performant bioresorbable scaffolds.

Acknowledgements The ABSORB DM Study team is grateful to Diagram BV Zwolle and all additional participating centres including their interventional cardiologists and study facilitators. These centres are Meander MC, Amersfoort, The Netherlands; CHR de la Citadelle, Liège, Belgium; CHU de Charleroi, Charleroi, Belgium; Clinique Saint-Luc Bouge, Namur, Belgium; Hagaziekenhuis, The Hague, The Netherlands; AZ Delta, Roeselare, Belgium; OLV Ziekenhuis, Aalst, Belgium; UZ Gent, Gent, Belgium; Amphia Ziekenhuis, Breda, The Netherlands; Haaglanden MC, The Hague, The Netherlands; OLVG, Amsterdam, The Netherlands, Ter Gooi Ziekenhuis, Hilversum, The Netherlands. 
Author contribution This manuscript is an original work and it is not under consideration for publication elsewhere. E. Kedhi designed the study, wrote the study protocol, codrafted the manuscript and gave final approval; T.M. Hommels drafted the manuscript; R.S. Hermanides and B. Berta helped by performing the statistical analysis; S. Rasoul, B. Berta, A.J.J. IJsselmuiden, G.A.J. Jessurun, E. Benit, B. Pereira and G. De Luca critically revised the manuscript for intellectual content.

Funding Maatschap Cardiologie Isala Hartcentrum, Isala Klinieken, Zwolle. Unrestricted research grant from Abbott Vascular.

Conflict of interest T.M. Hommels, R.S. Hermanides, S. Rasoul, B. Berta, A.J.J. IJsselmuiden, G.A.J. Jessurun, E. Benit, B. Pereira, G. De Luca and E. Kedhi declare that they have no competing interests.

Ethical standards The prospective study was performed in accordance with the Declaration of Helsinki (DoH) and was registered in the Netherlands Trial Register (NTR) acknowledged by the World Health Organisation (WHO) and International Committee of Medical Journal Editors (ICMJE). Approval for ethical committees was sought in all participating centres and countries. This clinical investigation did not test any new device. The ABSORB BVS and the ABSORB GT1 are $\mathrm{CE}$ marked products and were used widely in daily clinical practice all over the world from 2009 to 2017 . This clinical register does not involve a medicinal product and is therefore not subject to The European Clinical Trials Directive (2001/20/EC).

Open Access This article is distributed under the terms of the Creative Commons Attribution 4.0 International License (http://creativecommons.org/licenses/by/4.0/), which permits unrestricted use, distribution, and reproduction in any medium, provided you give appropriate credit to the original author(s) and the source, provide a link to the Creative Commons license, and indicate if changes were made.

\section{References}

1. Shaw JE, Sicree RA, Zimmet PZ. Global estimates of the prevalence of diabetes for 2010 and 2030. Diabetes Res Clin Pract. 2010;87:4-14.

2. Guariguata L, Whiting DR, Hambleton I, Beagley J, Linnenkamp U, Shaw JE. Global estimates of diabetes prevalence for 2013 and projections for 2035. Diabetes Res Clin Pract. 2014;103:137-49.

3. GuK,CowieC,Harris M. Mortalityin adultswithand without diabetes in a national cohort study of the US population, 1971-1993. Diabetes Care. IEEE Trans Med Imaging. 1998;21:1138:45.

4. Kannel WB, McGlee DL. Diabetes and glucose tolerance as risk factors for cardiovascular disease: the Framingham study. Diabetes Care. 1979;2:1201-1126.

5. Lee W, Cape D, Cheung A, Zinman B. Impact of diabetes mellitus on coronary artery disease in woman and men: a meta-analysis of prospective studies. Diabetes Care. 2000;23:962-8.

6. Hammoud T, Tanguay JF, Bourassa MG. Management of coronary artery disease: therapeutic options in patients with diabetes. JAm Coll Cardiol. 2000;36:355-65.

7. Stone GW, Kedhi E, Kereiakes DJ, et al. Differential clinical responses to everolimus-eluting and paclitaxel-eluting coronary stents in patients with and without diabetes mellitus. Circulation. 2011;124:893-900.
8. Jensen LO, Maeng M, Thayssen P, et al. Influence of diabetes mellitus on clinical outcomes following primary percutaneous coronary intervention in patients with STsegment elevation myocardial infarction. Am J Cardiol. 2012;109:629-35.

9. Diletti R, Onuma Y, Farooq V, et al. 6-month clinical outcomes following implantation of the bioresorbable everolimus-eluting vascular scaffold in vessels smaller or larger than $2.5 \mathrm{~mm}$. JAm Coll Cardiol. 2011;58:258-64.

10. Dudek D, Onuma Y, Ormiston JA, Thuesen L, MiquelHerbert K, Serruys PW. Four-year clinical follow-up of the ABSORB everolimus-eluting bioresorbable vascular scaffold in patients with de novo coronary artery disease: the ABSORB trial. EuroIntervention. 2012;7:1060-1.

11. Onuma Y, Serruys PW, Ormiston JA, et al. Three-year results of clinical follow-up after a bioresorbable everolimus-elutingscaffold in patients with denovo coronary artery disease: the ABSORB trial. EuroIntervention. 2010;6:447-53.

12. Serruys PW, Onuma Y, Dudek D, et al. Evaluation of the second generation of a bioresorbable everolimus-eluting vascular scaffold for the treatment of de novo coronary artery stenosis: 12-month clinical and imaging outcomes. JAm Coll Cardiol. 2011;58:1578-88.

13. Serruys PW, Ormiston JA, Onuma Y, et al. A bioabsorbable everolimus-eluting coronary stent system (ABSORB): 2-year outcomes and results from multiple imaging methods. Lancet. 2009;373:897-910.

14. Windecker S. The ABSORB cohort B trial: insights from longitudinal imaging follow-up from six months to three years. J Am Coll Cardiol. 2013;61:E1643-5.

15. Whitbourn RJ. TCT-31 ABSORB EXTEND: an interim report on the 24-month clinical outcomes from the first 250 patients enrolled. JAm Coll Cardiol. 2013;62:B11.

16. Tenekecioglu E, Farooq V, Bourantes CV, et al. Bioresorbable scaffolds: a new paradigm in percutaneous coronary intervention. Bmc Cardiovasc Disord. 2016;16:38.

17. Ellis SG, KereiakesDJ, MetzgerDC, etal. Everolimus-eluting bioresorbable scaffolds for coronary artery disease. NEngl J Med. 2015;373:1905-15.

18. KedhiE, GénéreuxP, Palmerini T, etal. Impact of coronarylesion complexity on drug-eluting stent outcomes in patients with and without diabetes mellitus: analysis from 18 pooled randomized trials. JAm Coll Cardiol. 2014;63:2111-8.

19. Kereiakes DJ, Ellis SG, Kimura T, et al. Efficacy and safety of the Absorb everolimus-eluting bioresorbable scaffold for treatment of patients with diabetes mellitus: results of the Absorb diabetic substudy. Jacc Cardiovasc Interv. 2017;10:42-9.

20. Grube E, Chevalier B, Guagliumi G, et al. The SPIRIT V diabetic study: a randomized clinical evaluation of the XIENCE V everolimus-eluting stent vs the TAXUS Liberté paclitaxel-eluting stent in diabetic patients with de novo coronary arterylesions. Am HeartJ. 2012;163:867-75.

21. Campos CM, Caixeta A, Franken M, et al. Risk and timing of clinical events according to diabetic status of patients treated with everolimus-eluting bioresorbable vascular scaffolds versus everolimus-eluting stent: 2-year results from a propensity score matched comparison of ABSORB EXTEND and SPIRIT trials. Catheter Cardiovasc Interv. 2018;91:387-95.

22. Investigators $B$. The final 10 -year follow-up results from the BARI randomized trial. J Am Coll Cardiol. 2007;49:1600:6.

23. Farhouh ME, Domanski M, Sleeper LA, et al. Strategies for multivessel revascularization in patients with diabetes. NEnglJ Med. 2012;367:2375-84.

24. Mohr FW, Morice MC, Kappetein AP, et al. Coronary artery bypass graft surgery versus percutaneous coronary 
intervention in patients with three-vessel disease and left main coronary disease: 5-year follow-up of therandomised, clinical SYNTAX trial. Lancet. 2013;381:629-38.

25. Goldman S, Zadina K, Moritz T, et al. Long-term patency of saphenous vein and left internal mammary artery grafts after coronary artery bypass surgery: results from a Department of Veterans Affairs Cooperative Study. J Am Coll Cardiol. 2004;44:2149-56.

26. Kereiakes DJ, Ellis SG, Metzger C. et al. 3-year clinical outcomes with everolimus-eluting bioresorbable coronary scaffolds: the ABSORB III trial. J Am Coll Cardiol. 2017;70:2852-62.
27. Wykrzykowska JJ, Kraak RP, Hofma SH, et al. Bioresorbable scaffolds versus metallic stents in routine PCI. N Engl J Med. 2017;376:2319-28.

28. Stone GW, Abizaid A, Onuma Y, et al. Effect of technique on outcomes following bioresorbable vascular scaffold implantation: analysis from the ABSORB trials. J Am Coll Cardiol. 2017;70:2863-74.

29. Collet C, Asano T, Miyazaki Y, et al. Late thrombotic events after bioresorbable scaffold implantation: a systematic review and meta-analysis of randomized clinical trials. Eur HeartJ.2017;38:2559-66. 